\title{
Why you should publish open access*
}

\author{
Gunther Maier ${ }^{1}$ \\ ${ }^{1}$ WU - Vienna University of Economics and Business, Vienna, Austria (email: gunther.maier@wu.ac.at) \\ Technical director of REGION and member of the editorial board
}

Received: 20 June 2015/Accepted: 20 June 2015

True open access journals like REGION differ from commercially published journals mainly by two characteristics:

1. They make all their content available to everyone free of charge;

2. They do not require authors to transfer rights on the article thus allowing others to use the results under liberal conditions; in REGION under the "Creative Commons Attribution-NonCommercial 4.0 International" (CC BY NC) License.

While the value of the first characteristic is immediately obvious to authors and readers, the implications of the second are less clear and less well understood. However, as the author of an article, it is most likely much more relevant for you than the first condition.

Why is this condition so important for you as an author? To understand this, let us briefly look into the standard procedures of a commercially published journal and compare it with those of an open access journal like REGION. When you publish your paper with a commercial journal, you typically have to sign a contract where you as the author transfer all the rights you have on your article to the publisher ${ }^{1}$. The key phrase in these contracts is "the sole right": It means that you not only grant the rights that you have on your article to the publisher of the journal - usually for nothing in return but that you as the author also give them up. This step not only limits others, it limits you as well. And this is not just a moral or ethical constraint like many of the standards that we as good members of the scientific community obey, it is a legal constraint. The rights that the publisher has acquired from you are protected by elaborate copyright regulations.

When you publish in REGION or any other open access journal with comparable regulations, you do not have to "grant and assign the sole right" on your article to the

\footnotetext{
* Information about the legal framework in Austria and about some potential copyright violation issues has been provided by Clemens Appl from WU's Department of Business, Employment and Social Security Law. His contribution is highly appreciated. All remaining errors are those of the author.

${ }^{1}$ A typical example: The author "grants and assigns" to the publisher "the sole, transferable right to reproduce, publish, distribute, transmit, make available or otherwise communicate to the public, publicly perform, archive, store, lease or lend and sell the Contribution or parts thereof individually or together with other works in any language, in all revisions and versions (including soft cover, book club and collected editions, anthologies, advance printing, reprints or print to order, microfilm editions, audiograms and videograms), in all forms and media of expression including in electronic form (including offline and online use, push or pull technologies, use in databases and networks for display, print and storing on any and all stationary or portable end user devices, e.g. text readers, audio, video or interactive devices, and for use in multimedia or interactive versions as well as for the display or transmission of the works or parts thereof in data networks or search engines), in whole, in part or in summarized form, in each case as now known or developed in the future, throughout the world and during the term of copyright protection as defined in domestic law, including the right to grant further time-limited or permanent rights". (Consent to Publish, Progress in Colloid and Polymer Science, a Springer Journal).
} 
publisher. The rights simply remain with you as the author. All you need to do is to agree that your article will be published under the license chosen by the journal; in the case of REGION, this license is the "Creative Commons Attribution-NonCommercial 4.0 International" or "CC BY NC" for short. When you submit an article, the difference may seem small and just a technical detail, but the implications are dramatic. In the case of an open access journal like REGION there are simply no copyright regulations that can get between you and your article, because all the rights still belong to you. Open access and creative commons licenses make it not only easier for others to use - with proper attribution - your intellectual property; they also make it easy for you. Since all the rights are still in your hands, you can use your article in any way you like without risking to get in conflict with the law, as is the case with a commercially published journal. Isn't this a pretty good reason to publish your article in an open access journal like REGION?

Copyright regulations are notoriously difficult and vary from country to country. In some countries they provide protection to a limited extent, or provide special regulations for academic research and teaching. Moreover, since your publishing contract may contain certain special clauses, general statements are impossible and every issue concerning what you can or cannot legally do with your article needs to be evaluated case by case. This in itself is a strong argument for publishing in an open access journal. Since you have not given up any rights in this case, you will not risk violating the publisher's rights and will not have to find out which legal regulation applies, what it includes, how the publishing contract must be interpreted, etc.

When you decide to go with a commercial publisher, the one thing that you should not do is to trust common sense. In copyright issues, small variations can make all the difference: Suppose you published a paper with a commercial publisher based on a standard publishing contract and you want to use this paper in class. According to the Austrian copyright regulations ${ }^{2}$, which are neither particularly strict nor liberal, you are allowed to print the paper and give the printouts to your students. You may also burn the respective file on CDs and hand these out. But when you upload the same file to a server, you violate the publisher's rights; this is even the case when students must be registered for your course and log in to access the file. But, maybe the library of your university has licensed this journal for all its faculty and students. Does this change the situation? Unfortunately, it does not. The library's contract allows you to get the text from the publisher's server, but not to republish it on another server. You may upload the link to the paper to your e-learning platform, but not the paper itself.

Your choice of type of journal for your article may have implications for what you can do in teaching as well, and may impede the e-learning initiative of your university. It may also interfere with how you have to design your presentation material and what you can do with it. According to the Austrian regulations, putting a quote from a copyright protected paper - be it your own or someone else's - onto your presentation slides is okay when it supports your scientific argument. But when you go a step further and make these presentation slides available on your homepage or on some other server, they are separated from the scientific argument and you violate the rights of the respective publisher.

So, if you have a choice, why should you publish your article in an open access rather than in a commercially published journal? Simply for two reasons: First, because you allow everybody to access your paper, not just those who are willing and able to pay. Second, because it does not force you to give up the rights you possess and it saves you a lot of potential trouble and headache with copyright regulations and copyright violations.

\footnotetext{
${ }^{2}$ The Austrian copyright regulations are currently under discussion and may be changed in the near future.
} 